Journal of Southeast Asian

\title{
A Qualitative Examination of the Psychosocial Adjustment of Khmer Refugees in Three Massachusetts Communities
}

Leakhena Nou

California State University, Inou@csulb.edu

Follow this and additional works at: https://docs.lib.purdue.edu/jsaaea

Part of the Asian American Studies Commons, Psychology Commons, and the Sociology Commons

\section{Recommended Citation}

Nou, Leakhena (2006) "A Qualitative Examination of the Psychosocial Adjustment of Khmer Refugees in Three Massachusetts Communities," Journal of Southeast Asian American Education and Advancement: Vol. 1 : Iss. 1 , Article 2.

DOI: 10.7771/2153-8999.1001

Available at: https://docs.lib.purdue.edu/jsaaea/vol1/iss1/2

This document has been made available through Purdue e-Pubs, a service of the Purdue University Libraries. Please contact epubs@purdue.edu for additional information.

This is an Open Access journal. This means that it uses a funding model that does not charge readers or their institutions for access. Readers may freely read, download, copy, distribute, print, search, or link to the full texts of articles. This journal is covered under the CC BY-NC-ND license. 


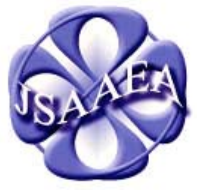

Volume 1
Journal of Southeast Asian American

\section{Education \& Advancement}

October 2006
A peer-reviewed

scholarly journal

published by the

National Association

for the Education \&

Advancement of

Cambodian, Laotian, and Vietnamese

Americans (NAFEA)

\author{
http://jsaaea.coehd.utsa.edu/index.php/JSAAEA
}

\title{
A Qualitative Examination of the Psychosocial Adjustment of Khmer Refugees in Three Massachusetts Communities*
}

\author{
Leakhena Nou \\ California State University, Long Beach
}

\begin{abstract}
This paper uses a sociological stress process model to explore the Khmer adult refugees' experience in Massachusetts. The analysis is based on the responses of three focus groups in the Khmer communities of Lowell, Lynn, and Revere, Massachusetts. The focus groups provided an in-depth understanding of sources of stress, stress mediators, and psychosocial adjustment/adaptational patterns for Khmer refugees who had experienced the Cambodian genocide. Symptoms and reactions associated with underlying causes of mental health problems had culturally specific relevance to physical illness and mental health.
\end{abstract}

\section{Introduction}

Cambodian refugees in Massachusetts experienced extensive and widespread exposure to multiple stressors prior to resettlement, especially in relation to the struggles and trauma they encountered during life under the Khmer Rouge regime. Whether exile-related, pre- and post-migration stressors played a role in the ability or inability of adult Khmer refugees to adjust successfully to life in the New England region of the United States remains poorly understood.

Most people living as refugees in a host society have been exposed to many pre-migration, trauma-related stressors, such as violations of human rights, loss of loved ones, and uprooting from one's homeland. They are also exposed to ongoing post-migration stressors in a new society, such as cultural adjustment and socioeconomic deprivations (e.g., Lie, Sveaass, \& Eilertsen, 2004).

Many Cambodian refugees experienced or witnessed traumatic events prior to fleeing Cambodia, such as family separation or loss of loved ones, torture, starvation, and rape. After resettlement, many encountered a loss of status, exposure to cultural differences, and racial animosity. The prevalence of specific post-trauma symptoms within refugee populations range as high as 30 percent to 86 percent (Nicholl \& Thompson, 2004). In a study of Southeast Asian

*Editors' Note: This article was originally published earlier this year (2006) as an Occasional Paper by the Institute for Asian American Studies (IAAS) at the University of Massachusetts, Boston (http://www.iaas.umb.edu/). The author and editors wish to thank IAAS for their permission to reprint Dr. Nou's work in the Journal of Southeast Asian American Education and Advancement. No changes other than reformatting to conform to the journal's style requirements have been made.

\section{(c)}

SORERIGHISRESERVEDReaders are free to copy, display, and distribute this article, as long as the work is attributed to the author(s) and the Journal of Southeast Asian American Education \& Advancement and the original publisher (IAAS) as indicated in the Editors' note above; it is distributed for non-commercial purposes only, and no alteration or transformation is made in the work. More details of this Creative Commons license are available at http://creativecommons.org/licenses/by-nc-nd/2.5/. All other uses must be approved by the author(s) or JSAAEA. 
refugees, Mollica, Wyshak, \& Lavelle (1987) found the Cambodian population to be the most traumatized of the refugees, having experienced an average of sixteen traumatic events, including deprivation, physical injury or torture, incarceration, and witnessing killing.

A major purpose of this paper is to document qualitative results regarding those factors that Cambodian, first-generation, adult refugees (ages 30-69) in Massachusetts consider to be culturally relevant to psychosocial adjustment and well-being. Rarely are indigenous Cambodian perspectives and experiences examined from an "insider's viewpoint" in the literature on Southeast Asian immigrants and stress-related research. This approach allows the researcher and respondents the opportunity to voice beliefs and perceptions about their stressors and responses, including the use and management of coping mechanisms. This approach is similar to the "testimony psychotherapy" concept as applied to Bosnian refugees, which finds that collective traumatization is as important as individual traumatization (Weine, Kulnovic, Pavkovic, \& Gibbons, 1998). The approach provides the possibility of exploring trauma in a way that encourages new collective understandings of history and shared identity.

These results may prove useful in developing policies to address adjustment needs and provide answers to questions posed by the dearth of information on Cambodian psychosocial wellbeing as understood by Cambodians. This research also intends to extend the external validity of stress studies to the Cambodian American population specifically.

It should be noted that the results reported in this paper are part of a larger examination of stress in the Massachusetts Khmer community that included a quantitative analysis of data gathered through a questionnaire administered to a sample of Khmer adults. This paper does not report on that data but instead on qualitative results from focus groups conducted before the survey was distributed.

The theoretical framework used to guide this study (see Figure 1) suggests that most Cambodians are caught between lingering, historical, painful memories, and the difficulties of adjusting to life in a new social environment. The framework suggests that those having little social support and using ineffective coping styles will show fewer positive psychosocial adjustments and adaptational patterns. In contrast, the framework suggests that individuals using effective coping styles and having good social support will show more positive psychosocial adjustments and adaptational patterns. The literature on stress often points out that stressors are precursors to physical and/or mental disorder and that repeated exposure (without positive coping strategies and social support) can be catastrophic (e.g., Gruen, Folkman, \& Lazarus, 1988; Lazarus, 1981).

The resilience or psychological thriving of Cambodian refugees has been explored in the literature. One master's thesis captures the concepts of thriving and resilience in cultural response to adversity and trauma (West, 2000). West's study investigated individual, contextual, and cultural factors that promote trauma-related resilience and positive growth among Cambodian survivors of the Cambodian genocide who resided in Lowell, Massachusetts and Phnom Penh, Cambodia $(\mathrm{N}=$ 42). Having a sense of optimism, social support, access to education, and Buddhist principles were found to be major predictors of resilience, and thriving in the face of stress. Cambodian respondents in the study reported that resilience and thriving had underlying connections to Buddhist teachings. West's study's results further highlight the way Cambodians serve as a resource and social catalyst for each other's healing recovery, as reflected in the concepts of resilience and thriving. The use of Cambodian imagery with historical and symbolic significance (such as photographs of Angkor Wat) contributed to wellness, resilience, and thriving. To assist Cambodians in the healing process, respondents in the study recommended integrating a cultural context into community programs, social resources, and health services. 
According to the 2000 U.S. Census statistics, reported by the Institute for Asian American Studies at the University of Massachusetts, Boston, Asian Americans are the fastest growing racial group in Massachusetts, having grown by nearly 68 percent since 1990. As a subgroup, Cambodians comprised 8.3 percent of the total, or 19,696 individuals. Due to underreporting, the actual figure is widely regarded as being much larger. The same study shows that Cambodians had the lowest incomes ( $\$ 25,000$ per year or lower) and lowest levels of educational attainment of all Asian groups (IAAS, 2004).

While statistics on the overall Cambodian population in Massachusetts reflect significant socioeconomic challenges, individual achievements need to be highlighted. For example, as the new generation has acquired high levels of education and training, many have entered professional fields ranging from academia, medicine, law, engineering, computer science, public office, social work, and law enforcement. On this same note, in recent decades the Cambodian communities in Lowell, Lynn, and Revere have seen a burgeoning of small businesses that actively cater to the needs of both Cambodian and non-Cambodian patrons. These small businesses offer a wide range of culturally relevant services, such as foods particular to the Cambodian cuisine, legal advice, auto repair, and community-based social and health services, which are often used by Cambodian patrons who have limited English language skills and mobility to access mainstream services. These successful cases demonstrate that, with time and access to resources, Cambodians may thrive in their new environments and be better able to cope with life's adversities.

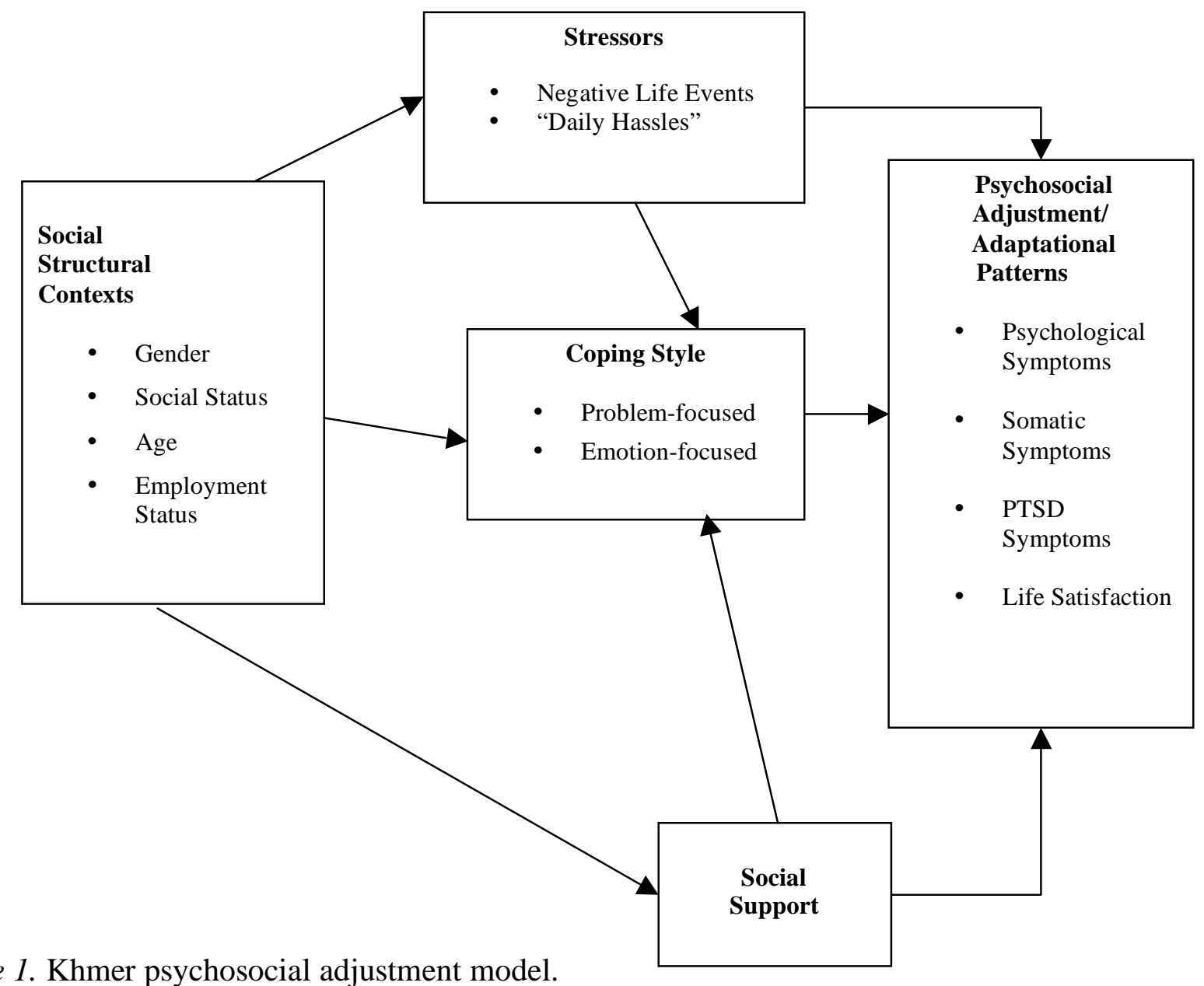

Figure 1. Khmer psychosocial adjustment model. 
Unfortunately, problems of low income and poor achievement in higher education persist. The results of this research suggest that the difficulties may stem from a relationship between exposures to stressors, use of ineffective coping strategies, and limited access to social supports that might aid psychological well-being and quality of life. It is this complex process that may hinder the process of successful life adjustment and assimilation in Massachusetts.

As mentioned earlier, while work by this author and others has provided quantitative support for the model (e.g., Nou, 2002; Marsella, 1984; Pearlin, Morton, Lieberman, Menaghan, \& Mullan, 1981), for the purposes of this paper, only qualitative results from a series of focus group discussions will be reported.

\section{Methodology}

Respondents for the study were recruited through grassroots contact in the Cambodian communities. To be included in the sample, persons needed to be survivors of the Khmer Rouge genocide (1975-1979), between the ages of 30 and 69, and living in Lowell, Lynn, or Revere. These three cities were chosen as designated research sites because of their large concentration of Cambodian residents.

A Cambodian American researcher served as the Principal Investigator (PI) for studying the psychosocial well-being of Cambodian communities in Massachusetts. The PI has specialized clinical and research training in mental health and has conducted research on the stress process among Cambodian youth in Cambodia.

Three other researchers participated in the study. A bilingual and bicultural researcher intimately familiar with Cambodian culture acted as a key community liaison and was critical in recruiting respondents for the project. Another researcher assisted with translations and helped to identify and recruit respondents with the support of community leaders in Lynn and Revere. Finally, another researcher served as senior translator for the project.

Using the group consensus translation approach, the researchers independently translated the search materials for this study, including the recruiting flyer, media announcement, confidential information sheet, and guiding research questions. At the end of each separate exercise, the two translators exchanged their work for review before coming together with the PI to discuss concerns of linguistic and cultural equivalency.

Participants were recruited through community leaders, informal groups, a community forum, and Khmer media and radio broadcasts. The same recruitment procedures were used for the qualitative and quantitative portions of the study. Participants had the option to engage in either portion of the study, or both if they wished.

An informational flyer, also transcribed into Khmer, was disseminated to various Khmer media and radio outlets. It read as follows:

\section{Dear fellow Khmer friends,}

Dr. Leakhena Nou, a postdoctoral fellow at the Institute for Asian American Studies at the University of Massachusetts, Boston, will be conducting a research study that examines the stressful experiences and adaptational patterns of Cambodian adults (ages 30-69) in the New England region (i.e., Lowell, Lynn, \& Revere). She is seeking respondents to be part of the study and your participation would help to ensure that the data collected reflect reality consistent with experiences as recounted 
by Cambodian adults in the region. This study would be an important sociological, community-based, empirical study conducted on the Cambodian population in the United States, and thus it is encouraged that adult members of the Khmer community in the three respective communities of Lowell, Lynn, and Revere respond to her request for participants to be part of the study. For more information about the study, please contact Dr. Nou at her office or by e-mail [telephone number and e-mail address provided].

Respondents who qualified and voluntarily agreed to be part of the study received an information sheet that described the purpose of the study and gave a brief background on the PI and her institutional affiliation. The information sheet further noted that the focus group discussions would last from one to three hours, participation was confidential and completely voluntary, and participants might withdraw from the discussion at any time without repercussions.

\section{Sample}

The sample for the focus groups consisted of fourteen respondents. Two separate focus group discussions were held, one in Lowell and the other in Lynn. There were no follow-up meetings for either location. The average time for each focus group discussion was between three and four hours. Recruiting respondents proved to be difficult perhaps because of the time commitment involved and sensitivity of the subject matter. Commitment to family obligations was also often reported as a reason for not being able to participate.

For respondents living in Lowell, a focus group meeting was held at the Metta Family Health Center in January 2005. Of those who voluntarily attended the focus group meeting, three were males and one was female. The three males had backgrounds in nursing, real estate business and youth outreach, and were in their thirties. The female respondent described her background as a community outreach worker and organizer, and was in her mid-thirties. All of the respondents arrived in the United States between 1980 and 1988, indicating they were survivors of the Khmer Rouge genocide.

Respondents from Lynn and Revere were asked to join a focus group discussion that was held in February 2005 at the Khmer Youth and Family Center in Lynn. Ten respondents participated. They ranged in age from their early thirties to their late sixties. Four were female and six were male. They had varied occupations, including small business ownership, translation services, community outreach, and social work. They reported arriving in the United States in the early to late 1980s, which qualified them as survivors of the Khmer Rouge tragedy.

\section{Procedure for Focus Group Discussions}

As a Cambodian American researcher, the PI, with support from a research assistant, facilitated bilingual discussions for both focus groups. The discussions were mainly held in English since a majority of the respondents understood that language. When older respondents had difficulty understanding abstract concepts, the PI spoke in Khmer.

A priority for the focus group protocol was to ensure that interview sessions were intimate and safe so that respondents felt comfortable speaking openly about successful and unsuccessful adjustment experiences, including their social observations of adaptational patterns in their respective communities. The PI made sure that each respondent had the opportunity to talk and 
share insights by systematically allowing for one person to respond at a time until everyone was called on. One effective approach the PI used to ensure that responses provided by participants were taken with all seriousness was to write their responses on the whiteboard and take diligent notes as each person shared his or her thoughts and insights. The visual presentations were critical to the success of the groups. They kept respondents informed and gave them a sense of control over and ownership of the research process and thus avoided the impression that the PI was influencing or manipulating results.

The questions guiding the semi-structured discussions largely came from the concepts as outlined in the theoretical framework in Figure 1. There were ten guiding research questions as listed below. The PI carefully provided explanations for each research question. Where appropriate, for purposes of clarity, a specific example was offered; for example, environmental pollution was cited as a daily hassle. Once the guiding research questions were defined, the respondents' general understanding, indigenous perceptions, and personal experiences of health and healthcare services, stressors, mediators, and symptoms of mental health status were explored. The discussions ended by examining whether respondents noted any gender or class differences in stress exposures, access to resources, or adaptational patterns/mental health outcomes.

\section{Guiding Research Questions}

1. What defines Khmer conceptions of physical and mental health/illness?

2. What are the healthcare needs for the Cambodian survivors' population?

3. What is your understanding of stress or stressors?

4. What is your understanding of negative life events?

5. What is your understanding of daily hassles?

6. What is your understanding of social support?

7. What is your understanding of coping strategies?

8. What is your understanding of life satisfaction?

9. What is your understanding of the stress process outcomes in terms of psychological and somatic symptoms?

10. Do you think gender/class differences play a role in people's different experiences with stressors, mediators, and adjustment/adaptational patterns?

\section{Qualitative Results}

Analysis of the focus group discussion results is organized in terms of three general components by using Figure 1 as the theoretical framework. The first is sources of stress, which is seen as the cause of illness and poor mental health. The second is mediators of stress, focusing on social support and coping style. The third concept is manifestations of stress, focusing on adaptation, which has as subcomponents psychosomatic symptoms, psychological distress, and life satisfaction.

The comments made in the focus groups were organized thematically. Responses were recorded as focus group respondents shared their answers to the guiding research questions with no specific ranking by items. Thematic clusters appear in Tables 1-20. 


\section{Sources of Stress}

This section explores various sources of stress in line with Cambodian thinking and experience. For the purposes of this research, stress is defined as a psychophysiological response to intense personal and social pressures that can cause imbalance in one's well-being. A general theoretical consensus holds that stressors motivate people to cope with behavioral demands while promoting emotional reactions to those demands. Consequently, a person is "at risk" for psychological distress when he or she is unable to cope effectively with a stressor (Lazarus \& Folkman, 1984).

An investigation of the respondents' thoughts regarding stress/stressors was essential in order to understand what they defined as stressors. According to our respondents in Lowell, Lynn, and Revere, the following are the stressors that put people "at risk" for developing psychological distress. Three separate social-psychological themes in relation to stressful experiences were identified (see Tables 1-3). They included cultural dissonance, emotional state of mind and wellbeing, and personal needs and obligations.

Table 1

Examples from Focus Groups Related to Cultural Dissonance

- Sometimes people are totally unaware of what constitutes stress or depression, partly because it is not common knowledge to express it publicly; stress is felt when people do not have sufficient income for living expenses; ${ }^{1}$

- Stress is caused when individuals lack understanding of the legal system and the ability to navigate it successfully, and thereby family relationships are strained.

Table 2

Examples from Focus Groups Related to Emotional State of Mind and Well-Being

- People feel stressed when they lack appetite for food or sex;

- When people always want to be alone;

- People are stressed when they are unable to cope effectively with simple life tasks such as not remembering medical appointments or meetings;

- Individuals who become socially withdrawn, as well as those with low self-esteem and loss of identity, may suffer from stress;

- Stressed-out people are those who feel indifferent to regular life activities such as finding no pleasure in simple things such as exercising;

- Pressure on the mind and difficulties in resolving personal problems that results in confusion and too many things in the mind (they described this as "head and chest about to explode");

- Feelings of constant worrying and frustration, chest tightness and headaches, depression, difficulty breathing and shortness of breath;

- Feelings of hopelessness or "no way out" (dead end mind-set);

- Having no one to listen;

- Thoughts of wanting to die or suicidal ideations such as to hang oneself or jump into the ocean;

- Experiencing panic attacks. 
Table 3

Examples from Focus Groups Related to Personal Needs and Obligations

- Stress is felt when people do not have sufficient income for living expenses;

- The lack of organization in the household and neglecting family obligations reflects that people are affected by stress;

- Having too many things to do.

A discussion with respondents on general thoughts on stressors led to a classification of specific negative life events and daily hassles, which at times overlap with each other. According to respondents in Lowell, Lynn, and Revere, there were discrete difficulties attached to negative life events and "daily hassles" often emerging within family and community life challenges that had connections to Cambodian political and historical consequences. The discrete problems for negative life events were associated with life domains ranging from effects of the Khmer Rouge trauma and resettlement difficulties (see Table 4), family and generational dissonance (see Table 5), emotional state of mind and well-being (see Table 6), and Cambodian and homeland politics (see Table 9). According to respondents in all three locations, daily hassles had five discrete challenging life domains that were associated with family and generational dissonance (see Table 5), emotional state of mind and well-being (see Table 6), personal immediate concerns (see Table 7), environmental and community concerns (see Table 8), and Cambodian and homeland politics (as described in the text).

Table 4

Examples from Focus Groups on Negative Life Events Related to Effects of the Khmer Rouge Trauma and Resettlement Difficulties

- The uprooting from one's homeland as a major life event;

- Feeling socially cast out, with no sense of belonging in the United States;

- Death of a loved one;

- Lack of trust among Cambodians;

- Destruction of Khmer culture and identity;

- Lack of education and basic resources for survival;

- The existence of social injustice and corruption in Cambodian society.

Table 5

Examples from Focus Groups on Negative Life Events and Daily Hassles Related to Family and Generational Dissonance

- Khmer parents experiencing a negative life event when they find out that their child commits a crime or engages in criminal behavior;

- Divorce or separation of parents can become a negative life event for the children;

- Fear of children joining gangs is a daily hassle;

- Generational conflicts in the family on a daily basis;

- Intergenerational cultural gaps such as children giving no respect to parents or not being disciplined;

- Lack of general understanding for the need of daily support in the family;

- The absence of a male figure in the household as a daily support in the family unit. 
Table 6

Examples from Focus Groups on Negative Life Events and Daily Hassles Related to Emotional State of Mind and Well-Being

- Becoming disabled;

- Loss of job and status;

- Having insufficient command of the English language to function on a daily basis in the United States can lead to a negative life event;

- The inability to sponsor family members from Cambodia can cause a negative life event as it reinforces family separation;

- A negative life event is the result of lack of sexual intimacy;

- Feelings of betrayal by a loved one;

- Having panic attacks;

- Not being awarded for good deeds;

- When a person has a bleak attitude or perception about the future;

- Feeling self-inadequate, such as aging and being incompetent;

- Negative behavioral patterns such as gambling, smoking, and infidelity.

Table 7

Examples from Focus Groups on Negative Life Events and Daily Hassles Related to Personal Immediate Concerns

- Lack of affordable housing;

- Lack of transportation;

- Having financial and social difficulties;

- Having fear of unemployment;

- Having family and work-related problems;

- Having limited education and a language barrier.

Table 8

Examples from Focus Groups on Daily Hassles Related to Environmental and Community

Concerns

- Daily traffic congestion;

- Safety concerns in the neighborhood;

- Cultural clash between American and Khmer worldviews;

- Lack of educational resources for the children;

- Khmer youth who engage in gang activities or deviant behaviors;

- Lack of trust, communication, respect, and the ability to reach out to each other, which by extension contributes to lying and manipulation in the Khmer community;

- The shame of being the focus of community gossip.

Similarly, respondents described feelings of hopelessness resulting from hearing negative reports about homeland politics and current affairs in Cambodia from Radio Free Asia or Voice of America broadcasts as a daily hassle. Respondents also feared persecution for speaking against the Cambodian government, even though they reside in the United States. 
Table 9

Examples from Focus Groups on Negative Life Events Related to Homeland Politics

- Remnants of traumatic memories linked to the Khmer Rouge were also described as negative life events, including parents abandoning their children because they cannot escape Cambodia with them;

- Witnessed cannibalism, (noted as a rare incident);

- A child who was forced to kill his own parents;

- Experiences with starvation;

- Negative events resulted in the suffering of the Khmer people;

- The death of a nation (quoted as "motherland falling into communist hands") as a consequence of territorial loss of Cambodian land to Thailand and Vietnam and the violation of Khmer human rights by Vietnamese soldiers.

Like negative life events, daily hassles are considered to be another dimension of stressors and are commonly cited in the stress literature. Kanner and his colleagues (Kanner, Coyne, Schaefer, \& Lazarus, 1981) proposed that the cumulative "little hassles" or day-to-day hassles (micro-stressors) have a greater impact on health than major life events. This statement clearly calls for consideration of daily stressors as significant for the Cambodian person (proximal variables) over major life events (distal variables).

Kanner et al. (1981) define "hassles" as "the irritating, frustrating demands that to some degree characterized everyday transactions with the environment" (p. 3), which include such examples as: trouble with the neighbors, children, relatives, traffic jams, the weather, too little time, too many things to do, and so forth. Hassles vary in meaning, intensity, and importance. They relate to relational processes (e.g., threat), or to the more stable characteristics of the individual (e.g., occupation). A related definition of "hassles" refers to "experiences and conditions of daily living that have been appraised as salient and harmful or threatening to the endorser's well-being" (Lazarus, 1981, p. 376).

The reports of daily hassles clearly reflect patterns of cultural experiences and conditions that were judged as significantly harmful or threatening to our respondents, which varied in meaning, intensity, and importance. The findings had similar, distinct themes parallel to that of negative life events.

\section{Mediators of Stress}

The second concept addressed in the focus groups is mediators of stress, focusing on social support and coping styles. Respondents who participated in the focus group discussions were asked to report anecdotally who they turn to for social support and the kinds of coping styles they utilized under stressful circumstances. The purpose of this discussion was to highlight the positive or neutral side to successful cultural adjustment as indicative of Cambodian resiliency in the face of adversity. This examination of the role of mediator is consistent with research by Strober (1994), which found social support was "one of the most effective factors for moderating stress, easing transitions and restoring previous adaptive mechanisms among Cambodian refugees" (p. 26). As a mediator of the stress-health relationship, focus group respondents reported that the Cambodian people used several sources of support (see Tables 10 and 13), including their significant others as well as community and social networks. They also sought help through religious coping strategies and, when necessary, from professionals. 
Table 10

Examples from Focus Groups Related to Significant Others

- Family members and immediate relatives;

- Lovers/boyfriends/girlfriends;

- Friends and neighbors;

- Visiting family members in Cambodia.

Table 11

Examples from Focus Groups Related to Community and Social Networks

- Local community organizations;

- Gambling friends;

- Fortune tellers/astrological readers;

- Teachers;

- The elderly;

- Individuals who can help find illegal employment (especially applicable for individuals without proper legal status who can be employed in a job that pays quick cash under the table);

- Drinking alcohol, gambling, eating, or going to strip clubs or parties;

- Consulting with business partners.

Table 12

Examples from Focus Groups Related to Religious Coping Strategies

- $\quad$ Buddhist monks and other spiritual/religious figures;

- Turn to prayer.

Table 13

Examples from Focus Groups Related to Professional Assistance

- Healthcare providers (who can assist with concerns related to social security, emergency situations, welfare benefits), healthcare providers in medical clinics or hospitals;

- State workers (who can assist with the processing of government funding, such as welfare benefits and subsidized housing).

According to McCubbin, Cauble, and Patterson (1982), social support is a coping resource. It is like a "social fund" from which people may draw when confronted with stressors. The effect of social support hinges on its value in promoting a positive sense of self and reinforcing one's ability to overcome stressful life circumstances (Cohen \& Wills, 1985; Pearlin et a1., 1981). According to Pearlin and associates, being embedded in a network is only the first step toward having access to support; the final step depends on the quality of relations one is able to develop within the network. The types of assistance provided by significant others include instrumental, informational, and/or emotional (House \& Kahn, 1985). From the operational framework of social support acting as a social fund within a network, it is clear that the Cambodians regard social support as a type of assistance that fulfills instrumental, informational, and/or emotional needs to overcome life's adversities.

The findings from the focus groups on social support correspond with a study by Strober (1994) that focused on social work intervention to alleviate Cambodian refugees' psychological distress in Prince George, Maryland. Strober found that persons who had more available and 
reciprocal family and community social supports also had lower levels of psychological distress and higher levels of acculturation adjustment. The author suggests examining an interactive family treatment model that takes into account family strengths or resiliency. With that in mind, we assert that social support from the family and community networks is essential to help Cambodian refugee adults. Thus, a positive relationship exists regarding social support and good mental health. According to McCubbin et al. (1982), there is evidence of a strong relationship between social support and a person's ability to adjust and cope with life changes.

The other component of stress mediation is coping style. Focus group respondents were asked to identify different coping strategies. The responses offered varied from addictive to selfdistraction coping strategies. When necessary, people made use of religion and community and/or hobbies or entertainment to help them cope.

Table 14

Examples from Focus Groups Related to Hobbies and Entertainment Coping Strategies

- People spending quality time with the family;

- People playing with their pets;

- People drinking tea;

- People going shopping;

- People going on picnics;

- People having sex on a regular basis;

- Gardening;

- Reading;

- Traveling;

- People engaging in sport activities or watching it on television;

- People exercising;

- People going to dancing parties or clubs;

- Eating, drinking, and gambling;

- People traveling to Cambodia or elsewhere overseas as a form of escape from life in the United States;

- People going to casinos to gamble, or gambling at home;

- Watching Chinese soap operas;

- Singing karaoke;

- People watching Khmer karaoke music or movie videos depicting Cambodian landscapes reminding them of the hardship of life in Cambodia, and thus reinforcing that life is better in the United States.

Respondents were asked about the different coping strategies people utilized when they were stressed. The responses in all three research sites were combined and are summarized in Tables 14-17. Their personal insights, along with observed pattern interactions they had with various members in the Cambodian community, are categorized into the following themes: hobbies and entertainment coping strategies, religious and community-seeking coping strategies, addictive coping strategies, and self-distracting coping strategies. 
Table 15

Examples from Focus Groups Related to Religious and Community-Seeking Coping Strategies

- Meditating;

- Speaking to wise people;

- Practicing meditation (e.g., Vipassana);

- Turning to God or religious prayers.

Table 16

Examples from Focus Groups Related to Addictive Coping Strategies

- Addiction to substances such as cigarettes, alcohol, and Ecstasy;

- Having violent tendencies.

Table 17

Examples from Focus Groups Related to Self-Distracting Coping Strategies

- Taking a cold shower;

- Doing excessive cleaning;

- Simply sitting at the beach and staring at the ocean or horizon.

These findings on coping correspond with Lazarus and Folkman's (1984) conceptualization of coping strategies as consisting of behavioral and/or cognitive attempts to manage specific situational demands, which are appraised as overwhelming or exceeding a person's adaptive ability. In a sense, with little control over exposure and experience with war and trauma, Cambodians have had to develop both behavioral and cognitive coping skills (including both problem- and emotionfocused coping styles) to adapt and carry on with life. As part of suffering, one coping style reported by the respondents included turning to religious prayers as indicative of one's acceptance of life's difficulty. This is largely based on a fatalistic Buddhist approach.

\section{Adaptation and Its Subcomponents: Psychosomatic Symptoms, Psychological Distress, and Life Satisfaction}

Examining the psychosomatic symptoms that result from stress overload is important in understanding the stress process as interpreted by respondents in Lowell. It should be noted that many of the reports on psychosomatic symptoms involve an overlap with general interpretations of stressors (including negative life events and daily hassles) and psychological and somatic symptoms connected to poor emotional states of mind and well-being (see Table 18).

Exploring psychosomatic symptoms in relation to perceptions and experiences with stressors and mediators, respondents in Lynn and Revere provided broad insights into psychological distress and sociocultural contextual perspectives (see Table 19).

Politically-charged manifestations of psychological symptoms were also brought up in the discussion including the loss of Cambodian resources and land, foreign intervention into Cambodian politics, the ineffective monarchy system in Cambodian society, and embarrassment caused by Khmers being slaves to the Vietnamese and Thai people.

Indicators of life satisfaction were described by respondents and are listed in Table 20. 
Table 18

Examples from Focus Groups Related to Poor Emotional States of Mind and Well-Being

- Fatalistic thinking;

- Social isolation;

- Feeling easily angered and agitated;

- No care for oneself or feeling hopelessness in one's life;

- Having suicidal ideations;

- Overdosing on dangerous substances;

- The inability to concentrate;

- Having urges for self-abuse such as cutting oneself;

- The inability to cope with daily tasks such as banking and childcare;

- Losing the desire for food and sex;

- Lack of physical activity;

- Lack of motivation to pursue one's career, education, or interact with the family;

- Loss of the desire to live;

- Hypochondriacal complaining without substantive medical confirmation or evidence;

- Feeling frequent tiredness;

- Withdrawal from religious activity.

Table 19

Examples from Focus Groups Related to Psychological Distress

- Feelings of panic attacks;

- Not feeling complete as a person;

- Having suicidal ideations;

- Being indecisive;

- Uncontrollably talking too much;

- Seeing lack of improvement (e.g., poverty and lack of education) in the community at the individual, community, and national levels that causes embarrassment and confusion in identity for the Khmer people;

- To be born as a Khmer is to have a "lost soul;" respondents reported that some older Khmer consider the lost soul to be a cause of psychosomatic symptoms.

Important components of the adaptational process are the perceptions of illness and of local health care providers as understood by respondents. Frye and D'Avanzo (1994) describe understanding and managing Cambodian illness as a quest for equilibrium (largely shaped by Buddhism), such that the mind, body, and spirit interact and integrate.

According to respondents in Lowell, Cambodian illness perceptions (both physical and mental) are interconnected to how individuals view and respond to their own health situation in relation to others. The following reports clarified the relationship between how an individual defines or acknowledges personal illness and when that person seeks help from community and social networks. Respondents defined three distinct categories of Khmer physical and mental illness (see Tables 21-23): self-image consciousness, coping strategies, and community and social networks. 
Table 20

Examples from Focus Groups Related to Life Satisfaction

- Being nice to others in general;

- Having a good paying job;

- Being healthy;

- Having cohesion and harmony in the family;

- Having good and reliable friends;

- Being debt-free;

- Having optimism about one's future;

- Having high self-esteem and striving for a better life;

- Having good housing;

- Having a good sexual partner;

- Having spiritual well-being;

- Appearing physically in good condition or attractive to others (e.g., being well-dressed and smelling good);

- Having people understand and love you;

- Having both parents alive;

- Providing a stable future for the children so they may secure the "American dream" for a better life and access to resources such as education;

- Traveling around the world;

- Sharing one's success story with others;

- Achieving one's life objectives;

- Having freedom.

- Having good relations with a life partner;

- Having money to live on and hopefully enough to brag about;

- Having fancy clothes, diamonds, and nice homes;

- Having total mind and body well-being;

- Having a successful career;

- Being able to speak freely;

- Receiving no bad news.

Table 21

Examples from Focus Groups Related to Self-Image Consciousness

- Pale physical appearance gives a clear indication someone is not physically well;

- When people have negative self-image and thus a diminished desire for bathing or caring for personal hygiene;

- An individual who wears the same clothes without changing them.

Responses in Lynn and Revere were similar to those in Lowell. Respondents had varied thoughts on conceptions of physical/mental health or illnesses as interpreted from an insider's perspective (see Table 24). All of the respondents reported that there is a strong stigma attached to seeking mental health treatment and services. This prevented them from asking for help to resolve psychosocial problems. 
Table 22

Examples from Focus Groups Related to Coping Strategies

- When people simply tell others they are not well;

- When people talk too much without thinking or not making sense;

- When people always want to be alone;

- When people ask for coining or massage;

- When people want to eat rice porridge;

- For relief people use Tiger Balm ${ }^{\mathrm{TM}}$, inhaling it through the nose and rubbing it on forehead temples.

Table 23

Examples from Focus Groups Related to Community and Social Networks

- When people seek fortune tellers to predict their future well-being as a way to make themselves feel better;

- Seeking advice from friends and members in the community on ways to feel better (e.g., pills/resources).

The fear of social rejection that prevented many from seeking professional help to deal with recurrent psychological traumas from the Khmer Rouge regime was reported as a cultural obstacle to having healthcare needs met. The reluctance of Cambodian refugees to seek treatment may be related to a fear of reviving thoughts of the past. Kinzie and his colleagues in their work with Southeast Asian refugees in Oregon found that interviews stirred active recollection of events (Kinzie, 1990). Kinzie reported, "Cambodian patients commonly gave vent to a full flood of emotions which could not be controlled" (p. 337), and symptoms were intensified without affording cathartic resolution (p. 345).

All of the respondents had a clear understanding that their symptoms and reactions were connected to traumatic experiences stemming from the Khmer Rouge regime such as starvation and having witnessed executions and deaths.

The endorsements of symptoms reported by our respondents are similar to findings by many scholars studying Cambodian psychosocial well-being. A recent study on the mental health of Cambodian refugees two decades after resettlement in the United States found high rates of posttraumatic stress disorder ([PTSD], 62 percent, weighted) and major depression (51 percent, weighted) (Marshall, Schell, Elliott, Berthold, \& Chun, 2005). In bivariate analyses, the same authors reported that being older, having poor English proficiency, being unemployed, being retired or disabled, and living in poverty were also associated with higher rates of PTSD and major depression. Marshall and his colleagues concluded by noting that, despite two decades having passed, the Cambodian population continues to have high levels of psychiatric disorders associated with trauma. Likewise, a study by Cheung and Spears (1995) in their examination of psychiatric morbidity and psychosocial factors among New Zealand Cambodians, found an association between chronic post-migration stressors and psychiatric morbidity. The same authors noted that "cultural stressors such as inadequate language skills, conflicts with perceived moral standards in New Zealand, and feelings of discrimination were frequently reported as important to their research participants" (p. 96). Both studies reflect a common pattern in which Cambodians suffer high levels of severe mental health problems. Respondents had important insights regarding the needs and deficits of the Western healthcare system serving the Cambodian population in Massachusetts. 
They felt that their status as minority immigrants has prevented them from receiving proper healthcare services. ${ }^{2}$

Table 24

Examples from Focus Groups Related to Cultural Reactions to Mental Health

- Depression;

- Poor sleep;

- Low energy;

- Headaches;

- Social isolation and withdrawal;

- Constantly worrying about things;

- Having short-term memory loss or forgetfulness;

- Having somatic complaints;

- Having a flat affect and not wanting to speak to people;

- Taking deep breaths/sighing;

- Having body aches;

- Feelings of being crazy or "chkuot."

When asked about healthcare risk factors for Cambodian survivors living in Lowell, focus group respondents in Lowell reported the following: lack of access or knowledge of healthcare resources, language barriers prevent people from getting the care they need, lack of direct services or advocacy on behalf of the Khmer clientele with limited English proficiency, need for appropriate cross-cultural understanding and respect from Western-trained healthcare providers, and lack of available traditional medicine incorporated as part of Western medicine. ${ }^{3}$

According to focus group respondents in Lynn and Revere, the healthcare needs of Cambodians are not adequately met partly due to language and cultural barriers between Khmer and Western viewpoints. They further asserted that there is insufficient advocacy for health education on behalf of the community and more help accessing and navigating health/mental health services is needed. They reported several reasons Cambodians fail to seek proper healthcare treatment, including lack of personal self-esteem, insight found through Vipassana meditation, and having little or no understanding about human anatomy and the benefits of exercise and balanced nutrition. One respondent specifically noted that the human anatomy as understood by a Cambodian person is often learned by touching and feeling, and is not conceptual. As a result, they do not get proper care.

Further comments by respondents indicated that limited knowledge about Khmer cultural and traditional ways on the part of Western healthcare providers is especially troubling. Khmer patients may resent not having more input regarding beneficial indigenous treatment practices as part of their overall healthcare plan. For instance, focus group respondents asserted that coining is one example of traditional medicine that should be incorporated into allopathic medicine.

Conversely, one respondent said that it is very hard to incorporate traditional methodologies such as coining into modern Western medicine because such practices could open Western healthcare institutions to lawsuits. Respondents noted an interesting point: Cambodians feel healthier when they are in Cambodia than when they are in the United States. Overall, the respondents concurred on all of the above factors as contributing to Cambodians' lack of initiative in seeking treatment and proposing solutions for their own healthcare concerns. For that reason, they are not maximizing the resources available to them as consumers and recipients of the Western healthcare system. ${ }^{4}$ 
Another area that was explored in the focus groups was the impact of gender and class on stress and the adaptation process. All of the respondents in Lowell agreed that women are likely to suffer more stress because Khmer culture traditionally expects them to be silent about personal and family issues, and as a result, they are more vulnerable than men are to developing mental health problems. Khmer women are socialized to take total responsibility for the family well-being and this adds to the burden of stressors they feel. ${ }^{5}$ With respect to class differences, respondents noted that individuals with more education are more immune to mental health consequences stemming from exposure to stressors. People who possess proper education and training can better adapt to social and life changes (e.g., adjusting to resettlement with few problems, job relocation). Overall, the respondents reported that people in general have an easier time coping with life stressors if they are connected to the community and thus are able to seek resources.

There were varied responses when respondents in Lynn and Revere were asked if gender and class differences played a role in how they experience stressors, mediators, and psychosomatic symptoms and life satisfaction. The difficulty adjusting from an agricultural society to an industrial one was identified as a major factor causing inequity in the stress experiences of different gender and class groups. All of the respondents agreed that women suffer more stress than men because of men's alcoholism and infidelity and because of domestic violence inflicted by Khmer men on their wives. According to respondents, Khmer women are usually expected to be tolerant of abuse (both emotional and physical), while men are expected to bring home the money. ${ }^{6}$ Regarding class differences, respondents indicated that lower-income people are more likely to suffer greater stress because of the lack of food, education, money, and financial security.

One of the main reasons for the sociological interest in "stressful life events" is the attempt to explain associations among the different factors of societal placement such as class, gender, and minority status and the different rates of psychosocial illness. Findings from early, causative frameworks (e.g., Menaghan, 1990; Pearlin, 1989) indicate that low-status groups showed higher rates of disorders due to their disproportionate encounters with difficult, harsh, or traumatic life conditions. Oftentimes, these elevated rates of disorder were attributed to lack of opportunities to gain access to social, economic, and/or personal resources, which would have enabled them to deal constructively with difficult life situations (Aneshensel, Lachenbruch, \& Rutter, 1991). The socially defined low status of Cambodians substantially limits their opportunity to gain access to social resources, including adequate healthcare services, and, thereby, subjects them to higher levels of stressful life events and psychosocial illnesses.

\section{Discussion}

As previously noted, the comments by the respondents provide firsthand accounts of Cambodians still haunted by the psycho-emotional traumas experienced under the Khmer Rouge, traumas that continue to create psychological stress even after thirty years of resettlement in the United States (see Table 19).

The horrific and terrifying events that the Cambodian people experienced during the Khmer Rouge regime affected both the individual and collective psyches of the people, damaging their memories for life and altering their present and future identities in irreparable ways. At the individual level, respondents reported having psychosomatic and psychological symptoms associated with fatalistic thinking, social isolation, and hopelessness in one's life. Thoughts of suicide and feeling that one possesses a lost soul were common. 
At the community level, respondents said that a lack of improvement in poverty and education at the individual, community, and national level causes embarrassment and confusion in identity for the Khmer people. Respondents continued to share culturally based reactions to mental health problems arising out of their Khmer Rouge and resettlement experiences. These experiences include depression, headaches, constant worrying, and having somatic complaints and feelings of being crazy. Respondents recommended putting Khmer Rouge war criminals on trial for their heinous brutalities against humanity as one healing solution to the perpetuation of the Cambodian trauma.

Qualitative results of this study are consistent with findings of other scholars studying the psychosocial well-being of Cambodian refugees. Carlson and Rosser-Hogan (1993) reported that 86 percent of Cambodians had high levels of anxiety and depression. The results reported by Cambodian-Australian respondents in Steven's study (2001) show similar psychological symptoms such as headaches (69 percent); poor concentration (58 percent); fatigue, tiredness, and lethargy (57 percent); memory loss (57 percent); and sleeping problems (45 percent). "Thinking too much" or "concentrating too hard in relation to worries about health" was reported as one of the causes of symptoms by respondents as noted in Steven's study. These findings concur with this study's results. Analysis of Cambodian adults in Utah in Blair's study (2000) revealed risk factors linked with post-traumatic stress disorder and depression - a greater number of resettlement stressors (e.g., worries about the future in the United States and lack of language competency in English) increased the risk of both PTSD and major depression, and having financial stress increased the risk of major depression. More recently, Marshall et al. (2005) assessed the prevalence of related illnesses and correlates of psychiatric disorders among Cambodian adult refugees in Long Beach, California twenty-five years after the Khmer Rouge era. They found that PTSD and major depression often existed concurrently ( $n=209 ; 42$ percent), and each reflected a strong doseresponse relationship with measures of traumatic exposure. PTSD and major depression were also found to be coupled with both pre- and post-migration trauma exposure and older age.

Few studies have examined specific stressful factors associated with Cambodian refugees and their vulnerability to pathology from a socially constructive point of view. This study has shown the Khmer stress process to be a complex phenomenon influenced by various social, cultural, environmental, historical, and political factors that subject the Cambodian people to pathology and adjustment difficulties. This complicated context influences respondents' perceptions of several important stressors (negative life events and daily hassles) that are worth noting. They are related to the effects of the Khmer Rouge and resettlement difficulties, including lack of trust among Cambodians, destruction of Khmer culture and identity, the existence of social injustice and corruption in Cambodian society, feeling socially outcast and without a sense of belonging in the United States, and lacking education and the basic resources for survival. Respondents also reported culturally specific stressors (negative life events and daily hassles) affected by environmental and community concerns such as cultural dissonance between American and Khmer ways of thinking, lack of trust and communication, lack of respect and the inability to reach out to each other that contributes to lying and manipulation in the Khmer community, and shame from community gossip.

The influence of homeland politics has become more apparent and stressful for Cambodians since the opening of Cambodia to the international world. This is not only true among Cambodian refugees in the United States but also those in France. Serge Thion (1993) asserted that among Cambodian refugees in France, politics attracts more people than religion. Thion described a pattern of fast growing political groups and cultural associations focused on a distinct political 
agenda, but with no prospect of curing the disease of political life in the homeland. With regard to the sample in Lowell, Lynn, and Revere, the ability to travel back and forth as a transnational between two homes (Cambodia and the United States) not only opened up possibilities for communication with loved ones but also sparked political aspirations, especially for the men. Some respondents viewed visiting families in Cambodia as a way to escape modern life stressors in the United States, while others felt a sense of hopelessness arising out of homeland politics. Homeland politics affected one family in a serious way when the husband opted to leave his family in the United States to start a new life as a politician in Cambodia.

The results also showed examples of culturally resilient responses that result in thriving, even in the face of demons from the past and uncertain life circumstances in the host society in the present. The approach used to analyze resilient responses is consistent with Janoff-Bulman's (1992) concept of social constructivism, which essentially encourages victims to psychologically reconstruct meanings for their traumatic experiences that are in line with their cultural values and beliefs.

In our examination of the role of mediators in the stress-health relationship, focus group respondents reported using several sources of social support. These included significant others such as family and friends. Respondents also turned to community and social networks such as seeking advice from fortune tellers or the elderly and support by means of religious coping strategies such as asking guidance from Buddhist monks and healthcare or social service professionals. One example of help was assistance with paperwork for welfare benefits and subsidized housing.

Other forms of stress mediators reported by respondents were coping strategies. The responses provided by respondents included hobbies and entertainment coping strategies, such as people going to casinos to gamble, or singing karaoke; religious and community coping strategies, such as meditating; addictive coping strategies, such as smoking or drinking alcohol; and distracting coping strategies, such as doing excessive cleaning.

The respondents evidently understand that the negative impact of social stressors on Cambodian refugee communities is due to the inadequate response by the host society. They cited such examples as language and cultural barriers and lack of direct healthcare services or advocacy on behalf of the Khmer clientele. The misguided responses of Western healthcare practitioners, in the view of many respondents, have created a set of services that are not useful to a vulnerable population traumatized by near extinction. It is very obvious that the host community has not sufficiently provided the Cambodians with needed services as many continue to battle psychological and emotional scars left while facing resettlement challenges. This assessment matches the conclusion drawn by Marshall, et al. (2005). They noted that:

The pervasiveness of psychiatric disorders raises questions about the adequacy of existing mental health resources in this community. Addressing this high level of need may require additional research to identify barriers to seeking services as well as efforts at improving treatment for this population. (p. 578)

The current study shows the cultural basis for the barriers to seeking services as suggested by Marshall and his colleagues.

When asked to list specific indicators of life satisfaction in the face of exposure to stressors, respondents gave interesting and very practical examples such as having self-esteem and being optimistic about one's future, having good housing conditions, having freedom, having a balanced body and mind. 
In terms of the impact of gender and class on the stress process, respondents clearly understood that women and individuals from lower-status groups are more at risk of developing mental health problems.

One major limitation of this study is that while some underlying contextual factors were examined (e.g., gender and social status), others were overlooked for practical reasons (e.g., personality characteristics - extroversion vs. introversion, ethnocultural identity). Perhaps examining different personality characteristics could help to explain variations in individual responses to stress exposure, distress, and use of mediators. The cross-sectional approach with a small sample size in the focus group did not allow for statistical validation of results for specific endorsement of symptoms.

\section{Conclusion}

This research has shown that Cambodians in Massachusetts continue to encounter life challenges as they try to figure out and establish their identity as refugees. Their difficulties are many. Most are linked to Cambodia's history and the political events that forced them to emigrate as refugees, often ill-equipped to deal with the harsh realities of modernity in the host society, and unable to fully grasp local and national policies that control their access to educational and healthcare resources.

The multifaceted and multileveled historical and political problems are often magnified by lack of trust and respect for each other, causing deterioration in ethnocultural identity and social breakdown. These concerns were reported by respondents as both examples of negative life events and as daily stressors. The intergenerational and intercultural conflicts between parents and children are very real concerns. Many youth find themselves caught between a desire to assimilate to American culture and a wish to search for their own Cambodian identity. The resulting cultural dissonance is heightened when children do not show respect to parents and when parents are unable to discipline their children.

Resettlement of Cambodian refugees has been fraught with the continual challenges of psychosocial adjustment, and has often resulted in negative adaptational patterns. Some respondents spoke of gambling, drug addiction, and suicidal ideations. As refugee transplants in a Western society entirely different from their native Cambodian culture, many have shown resilience in acquiring skills in problem-solving (e.g., spending quality time with the family) and emotion-focused coping styles (e.g., going to the beach to reflect and meditate).

Overall, this research offers vital insights into the psychosocial well-being of Cambodians thirty years after resettlement. Intimate focus group discussions were found to provide an effective way to study adaptational patterns of Cambodian refugees in Massachusetts. Given the opportunity to exchange ideas and define their needs, Cambodians demonstrate deep insight into their situation as refugees. Cambodians in the diaspora will continue to be marginalized as immigrants if they do not participate in the democratic process of the United States. As such, service providers are encouraged to assist Cambodians to be proactive and not reactive in healing their past wounds as they adjust to modern life as Americans.

The observations made by focus group participants have given us a useful glimpse of the silent suffering of the adult Cambodian refugee population in Massachusetts. The focus group approach can be used as a model to study the stress process in other Cambodians in the diaspora. It is hoped that this research will serve as a way of giving back to the community by ensuring that the results offer indigenous perspectives that may assist in the construction of government policies and services to meet the needs of Cambodian Americans. 


\section{References}

Aneshensel, C. S., Lachenbruch, P. A., \& Rutter, C. M. (1991). Social structure, stress, and mental health: Competing conceptual and analytical models. American Sociological Review, 56, 166-178.

Blair, R. G. (2000). Risk factors associated with PTSD and major depression among Cambodian refugees in Utah. Health and Social Work, 25(1), 23-30.

Carlson, E., \& Rosser-Hogan, E. (1993). Mental health status of Cambodian refugees ten years after leaving their homes. American Journal of Orthopsychiatry, 63, 223-231.

Cohen, S., \& Wills, T. A. (1985). Stress, social support, and the buffering hypothesis. Psychological Bulletin, 98, 310-357.

Cheung, P., \& Spears, G. (1995). Psychiatric morbidity among New Zealand Cambodians: The role of psychosocial factors. Social Psychiatry and Psychiatric Epidemiology, 30(2), 92-97.

D'Avanzo, C. E., \& Barab, S. A. (1998). Depression and anxiety among Cambodian refugee women in France and the United States. Mental Health Nursing, 19, 541-556.

Frye, B. A., \& D'Avanzo, C. E. (1994). Themes in managing culturally defined illness in the Cambodian refugee family. Journal of Community Health Nursing, 11(2), 89-98.

Gruen, R. J., Folkman, S., \& Lazarus, R. S. (1988). Centrality and individua1 differences in the meaning of daily hassles. Journal of Personality, 56(4), 743-762.

House, J. S., \& Kahn, K. R. (1985). Measures and concepts of social support. In S. Cohen \& S. L. Syme (Eds.), Social Support and Health (pp. 83-108). Orlando, FL: Academic Press.

Institute for Asian American Studies. (June, 2004). Community Profiles in Massachusetts. University of Massachusetts, Boston.

Janoff-Bulman, R. (1992). Shattered assumptions: Towards a new psychology of trauma. New York University Press.

Kanner, A., Coyne, J. C., Schaefer, C., \& Lazarus, R. S. (1981). Comparisons of two modes of stress measurement: Daily hassles and uplifts versus major life events. Journal of Behavioral Medicine, 4, 1-39.

Kemp, C. (1985). Cambodian refugee health care beliefs and practices. Journal of Community Health Nursing, 2(1), 41-52.

Kinzie, J. D. (1990). The concentration camp syndrome among Cambodian refugees. In D. A. Ablin \& M. Hood (Eds.), The Cambodian Agony (p.332-352). Armonk, NY: M.E. Sharpe.

Lazarus R. S., \& Folkman, S. (1984). Stress, appraisal, and coping. New York: Springer.

Lazarus, R. S. (1981). The stress and coping paradigm. In C. Bisdorfer, C. Cohen, A. Kleinman, \& P. Maxim (Eds.), Conceptual models for psychopathology (pp. 173-209). New York: Spectrum.

Lie, B., Sveaass, N., \& Eilertsen D. E. (2004). Family, activity, and stress reactions in exile. Community, Work and Family, 7(3), 327-350.

Lu, L. (1991). Daily hassles and mental health: A longitudinal study. British Journal of Psychology, 82, 441-447.

Marsella, A. J. (1984). An interactional theory of psychopathology. In B. Lubin \& W. Connor (Eds.), Ecological Approaches to Clinical and Community Psychology (pp. 233-250). New York: John Wiley \& Sons, Inc.

Marshall, G. N., Schell, T. L., Berthold, S. M., \& Chun, C. A. (2005). Mental health of Cambodian refugees two decades after resettlement in the United States. Journal of American Medical Association, 294(9), 571-579. 
McCubbin, H., Cauble, A., \& Patterson, J. (1982). Family stress, coping, and social support. Springfield, IL: C. C. Thomas.

Menaghan, E. G. (1990). Social stress and individual stress. Research in Community Mental Health, 6, 107-141.

Mollica, R. Wyshak, G., \& Lavelle, J. (1987). Psychological impact of war trauma and torture on Southeast Asian refugees. American Journal of Psychiatry, 144, 1567-1572.

Nicholl, C., \& Thompson, A. (2004). The psychological treatment of post-traumatic stress disorder (PTSD) in adult refugees: A review of the current state of psychological therapies. Journal of Mental Health, 13(4), 351-362.

Nou, L. (2002). Social support, coping, and psychosocial adjustment of Khmer university, college, and technical students in modern Cambodia: A sociological study. Department of Sociology. Doctoral dissertation, University of Hawaii at Manoa.

Pearlin, L. I. (1989). The sociological study of stress. Journal of Health and Social Behavior, 30, 241-256.

Pearlin, L. I., Morton, A., Lieberman, Menaghan, E. G., \& Mullan, J. T. (1981). The stress process Journal of Health and Social Behavior, 22, 337-356.

Rita, C. Y. C. (2001). Psychosocial adjustment of Cambodian refugee women: Implications for mental health counseling. Journal of Mental Health Counseling, 23(2), 115-126.

Stevens, C. A. (2001). Perspectives on the meanings of symptoms among Cambodian refugees. Journal of Sociology, 37, 81-96.

Strober, S. B. (1994). Social work intervention to alleviate Cambodian refugee psychological distress. International Social Work, 37, 23-35.

Thion, S. (1993). Watching Cambodia. Bangkok; White Lotus Co.

Weine, S. M., Kulnovic, A., Pavkovic, I., \& Gibbons, R. (1998). Testimony psychotherapy in Bosnian refugees: A pilot study. American Journal of Psychiatry, 155, 1720-1726.

West, C. D. (2000). Pathways of thriving and resilience: Growth responses to adversity and trauma in two Cambodian communities: A comparative study between Lowell, Massachusetts and Phnom Penh, Cambodia. Unpublished manuscript, University of Massachusetts, Lowell.

\section{Acknowledgments}

This study was conducted with financial and logistical support from the Institute for Asian American Studies at the University of Massachusetts, Boston. Thanks are due to our core research team who devoted countless hours and commitment to the project: Bou Lim, Kirirath Saing, and Stephen Thong; to the Cambodian community for their cooperation, such as Dorcas C. Grigg-Saito, Mr. Sonith Peou, and Mr. Chan Touch at the Metta Health Center in Lowell; as well as to countless others and to community organizations that gave unconditional support for the study; to mentors and colleagues for their valuable intellectual insights and support, including Dr. Anthony Marsella, Dr. Michael Mend, and Dr. Patrick Clarkin; Dr. Peter Kiang; and Dr. Jack Fong. We are also greatly indebted to the research participants, without whom this study would not have been possible.

\section{Endnotes}

\footnotetext{
${ }^{1}$ This dilemma begs the question: How do social scientists reconcile the fact that some Khmer do not know what stress is, yet they feel it and are poor?
} 


\begin{abstract}
${ }^{2}$ The assessment made by our respondents is supported by Marshall et al.'s research (2005) on the mental health of Cambodian refugees, which raised questions about the adequacy of existing mental health resources in this community. On a larger public policy level, they further reported that U.S. government policies have not met the needs of refugee resettlement. They suggested asylum policies for future refugees by removing them from life-threatening circumstances as well as assisting in their capacity to promote the long-term health and well-being of the refugees.

${ }^{3}$ The reports on the risk factors associated with poor healthcare delivery services by our respondents overlap with a study on managing culturally defined illness in the Cambodian family, which found that as a response to illness, Cambodians tend to cling to traditional practices in an effort to hold on to cultural viability and integrity (Frye \& D'Avanzo, 1994).

${ }^{4}$ The point raised about Cambodian lack of self-initiative to seek treatment and propose solutions for their own healthcare is in line with Kemp's research (1985) on Cambodian refugee health care beliefs and practices. Kemp asserted that "Cambodians are not aggressive in seeking care; case finding and research is essential to understanding what health problems exist and what beliefs and systems impede obtaining care. When primary care is obtained, it is of paramount importance that follow-up evaluation and teaching be done. Working with refugees is sometimes difficult and slow, but the difficulties are balanced by the great progress that can be made" (p. 52).

${ }^{5}$ Mollica, Lavelle, and Khoun found Cambodian women specifically as being at greatest risk for development of mental health problems associated with their Khmer Rouge experience (cited in Chung, 2001). D'Avanzo and Barab (1998) found high levels of depression and anxiety among Cambodian women refugees in France and the United States.

${ }^{6}$ Cambodian women have suffered widespread trauma; for example, Mollica found that 95 percent of Cambodian women have been sexually abused or raped (cited in Chung, 2001).
\end{abstract}

\title{
About the Author
}

Dr. Leakhena Nou joined the faculty as an Assistant Professor of Sociology at California State University, Long Beach (CSULB) in fall of 2005. Previously, she was a Postdoctoral Fellow at the Institute for Asian American Studies at the University of Massachusetts, Boston, during which time she conducted the study presented in this report.

Dr. Nou has also served as Dean of the College of Social Sciences at the University of Cambodia, and as a visiting faculty member at the University of Illinois at Urbana-Champaign's School of Social Work. She holds a Ph.D. and an M.A. in Sociology from the University of Hawai'i at Manoa, and an M.S.W. from Columbia University.

Nou is on the board of the Southeast Asia Resource Action Center based in Washington D.C., and is a member of the University of California Irvine Libraries Southeast Asian Archive Advisory Board. She also serves as Health Expert for the National Cambodian American Health Initiative. 


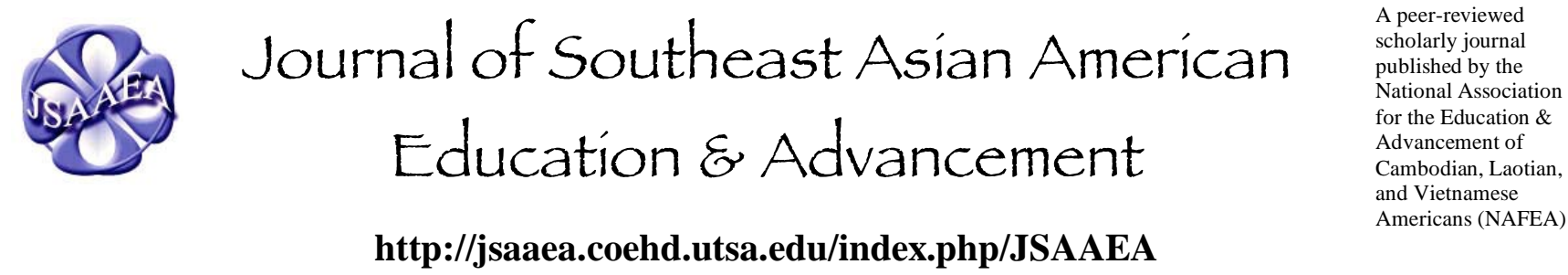

Editor

Dr. Wayne E. Wright

University of Texas, San Antonio

Associate Editors

Dr. Chhany Sak-Humphry

University of Hawaii

Dr. KimOanh Nguyen-Lam

California State University, Long Beach

Book Review Editor

Dr. Leslie Turpin

School for International Training

Creative Works Editor

Phouang Hamilton

Washington Office of Superintendent of Public Instruction

Special Advisor

Anne Frank

University of California, Irvine Southeast Asian Archives

Editorial Assistant

James Knaack

University of Texas, San Antonio

Comments and questions for the editorial staff may be directed to jsaaea@ lists.sis.utsa.edu.

\section{Editorial Review Board}

\author{
Dr. Carl L. Bankston III \\ Tulane University \\ Dr. Pollie Bith-Melander \\ San Jose State University \\ Dr. Phala Chea \\ Lowell Public Schools \\ Dr. George Chigas \\ University of Massachusetts, Lowell \\ Dr. Changming Duan \\ University of Missouri, Kansas City
}

\author{
Dr. Sophal Ear \\ Syracuse University
}

Dr. Nancy H. Hornberger University of Pennsylvania

Dr. Samlong Inthaly

Minneapolis Public Schools

Dr. Peter Nien-Chu Kiang

University of Massachusetts, Boston

Dr. Kevin K. Kumashiro

University of Illinois, Chicago 
Dr. Stacey Lee

University of Wisconsin, Madison

Dr. David Chanpannha Ley

Montgomery County Public Schools

Dr. Sue Needham

California State University, Dominguez Hills

Dr. Bic Ngo

University of Wisconsin, Madison

Dr. Max Niedzwiecki

Independent Scholar

Dr. Leakhena Nou

California State University, Long Beach

Dr. Clara Park

California State University, Northridge

Dr. Mark Pfeifer

Texas A\&M University, Corpus Christi

Dr. Loan T. Phan

University of New Hampshire

Dr. Bounlieng Phommasouvanh

Minnesota Department of Education

Dr. Karen Quintiliani

California State University, Long Beach
Dr. Kalyani Rai

University of Wisconsin, Milwaukee

Dr. Fay Shin

California State University, Long Beach

Dr. Nancy J. Smith-Hefner

Boston University

Dr. Yer J. Thao

Portland State University

Dr. Myluong Tran

San Diego State University

Dr. Khatharya Um

University of California, Berkeley

Dr. Linda Trinh Vo

University of California, Irvine

Dr. Terrence G. Wiley

Arizona State University

Dr. Zha Blong Xiong

University of Minnesota

Dr. Kou Yang

California State University, Stanislaus

\title{
Doctoral Student Editorial Review Board
}

\author{
Keo Chea \\ University of Pennsylvania \\ Vichet Chhuon \\ University of California, Santa Barbara \\ Loan Dao \\ University of California, Berkeley \\ Annie BichLoan Duong \\ San Joaquin County Office of Education \\ Ha Lam \\ Arizona State University \\ Vanna Som \\ Harvard University
}

\author{
Giang Tang \\ University of Minnesota \\ Layheng Ting \\ State University of New York, Albany \\ Loan Tran \\ University of California, Santa Barbara \\ Phitsamay Sychitkokhong Uy \\ Harvard University \\ Yang Sao Xiong \\ University of California, Los Angeles
}

